\title{
Fixation of Subtrochantric Fractures Using Distal Femoral Locking Compression Plate of Contralateral Side
}

\author{
${ }^{*}$ Roel Langshong ${ }^{1}$,B.Punithavasanthan ${ }^{2}$,Pheiroijam Bhupes ${ }^{3}$, S Nongthon \\ $\operatorname{singh}^{4}$, Rajkumar Debbarma ${ }^{2}$,Prabhu shrinivas prashanth ${ }^{2}$, Prabhat rai $^{2}$, \\ Shams gulrez ${ }^{2}$,Dilip soring ${ }^{2}$,Temjen sunep ${ }^{2}$. \\ ${ }^{1}$ Assistant Professor,Department of orthopaedics, Regional Institute of Medical Sciences,Imphal. \\ ${ }^{2}$ Postgraduate Trainee,Department Of Orthopaedics, Regional Institute Of Medical Sciences,Imphal. \\ ${ }^{3}$ Senior Resident,Department Of Orthopaedics, Regional Institute Of Medical Sciences, Imphal. \\ ${ }^{4}$ Professor,Department Of Orthopaedics,Regional Institute Of Medical Scinces,Imphal. \\ Corresponding author: * Roel Langshong
}

\begin{abstract}
:
Introduction: Different implants are available to internally fix subtrochantric fracture of femur, due to anatomical \& biomechanical reasons, the sub-trochanteric femoral fracture still a challenge for Orthopaedic Surgeons

Objective: The purpose of this study was to evaluate the outcome in early treatment of subtrochanteric fractures of femur with distal femoral locking compression plate of contralateral side.

Methods: Thirty patients were included in this study. Sixteen patients (53.3\%) had AO type 32B fracture, while nine patients (30\%) and five patients (16.6\%) were classified as AO type $32 \mathrm{~A}$ and $32 \mathrm{C}$ respectively. Road traffic accidents - accounted for 21 patients (70\%). Mean follow-ups were $11 \pm 6$ months (range 6 to 19 months). 27 fractures (90\%) achieved union, average union time in 14.5 weeks Ranging from 10 weeks to 20 weeks. while three patients (10\%) had complications. In one patient the plate had broken, one had broken screw and nonunion of the fracture. At the end of the follow-ups, 29 patients (96.6\%) were community ambulators.The Modified Harris hip score (MMHS) was used to evaluate the functional outcome of surgery

Conclusion: We conclude that distal femoral locking compression plate of contra lateral side is as effective as $P F-L C P$ and is an effective alternative treatment for subtrochanteric fractures when properly performed.
\end{abstract}

Keywords: subtrochanteric fracture, contralateral distal femoral locking compression plate, modified harris hip score.

\section{Introduction}

Subtrochanteric fractures account for $10-34 \%$ of all hip fractures ${ }^{[1]}$. Surgical treatment is the preferred method for subtrochanteric femoral fractures and a variety of implants are used. These implants fall into two main categories, intramedullary and extramedullary. Intramedullary fixation is associated with short operative time and minimal blood loss and has better biomechanical properties when compared with extramedullary fixation. However, they have their own technical difficulties and complications ${ }^{[1,2]}$. Extramedullary devices such as dynamic condylar screws and $95^{\circ}$ condylar blade-plates provide strong fixation in the cancellous bone of the neck and head with considerable rotational stability. Their disadvantages are longer operating time, technically demanding, extensive devascularisation, higher infection rate, delayed weight bearing, medial instability, refracture after plate removal and surgical approach ${ }^{[3]}$. Although anatomic plates have been developed, proximal trochanteric fixation is not always straightforward, especially when the fracture line extends proximally. Proximal fixation is important in these cases. We therefore recommend using the Distal Femoral LCP (locking compression plate) in a reversed situation: e.g., right plate for left hip. The aim is to enhance trochanteric fixation by increasing the number of proximal screws ${ }^{[5]}$.

\section{Methods And Materials}

This was a prospective study of patients - aged 15 years or older, who had sustained subtrochanteric fractures (AO type 32A-C) and were treated with distal femoral locking compression plate of contra lateral side between june2014 and june 2016. The patients with pathologic fractures (other than due to osteoporosis) were excluded. Distal femoral plates are LCP system. Head features threaded holes which are total 7 in number. Central 3 holes allows placement of $6.5 \mathrm{~mm}$ cancellous screws and remaining holes are for $4.9 \mathrm{~mm}$ locking head cortical screws. Shaft portion of the plate features combi holes allows fixation with $4.9 \mathrm{~mm}$ locking head screws or $4.5 \mathrm{~mm}$ non locking conventional screws. The most distal hole allows the use of a Kirschner wire for temporary fixation to achieve correct positioning of the plate. The plate is fitted in a "reverse" position. The 
plate is anatomically precontoured for the metaphysis of the proximal femur. Either anterior or posterior locking threaded holes of the head of the plate can be left unengaged depending on the area covering the greater trochanter.

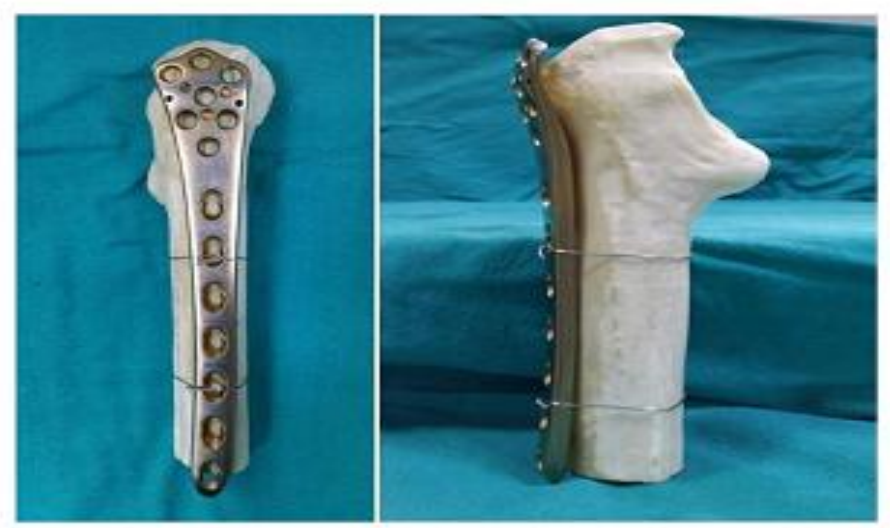

$$
\begin{aligned}
& \text { Figure 1: showing perfect contouring of } \\
& \text { DF-LCP in proximal femoral area. }
\end{aligned}
$$

\section{Operative procedure}

As soon as the patient is brought to casualty, patient's airway, breathing and circulation were assessed. Plain radiographs AP view showing both hip joints and lateral view of affected hip joint were taken to assess the extent of fracture comminution, geometry and the dimensions of the fracture. After admission temporary skin traction was applied, a detailed history was taken, relating to the age, sex, and occupation, mode of injury, past and associated medical illness. Routine investigations were done. After taking informed consent, a pre-operative anesthetic evaluation was done and pre-op planning of surgery was made. All the fractures were classified according to A.O classification and suitable length of screws along with contralateral sided plates were prescribed. All the patients were given prophylactic dose of antibiotics to avoid infection. General / Spinal anaesthesia was administered, and patient was placed in supine position on a radiolucent table, traction table was applied. Through a standard lateral approach open reduction was done . In case of two part or three part fractures it was temporarily held by k wires. The plate was fitted in a "reverse" position. The plate was anatomically precontoured for the metaphysis of the proximal femur. After ensuring proper reduction in image intensifier plate was fixed with screws. Quadriceps exercises were encouraged postoperatively on the next day of operation. Prophylactic antibiotics second generation or third generation cephalosporins were used for 72 hours depending upon the conditions of patients and type of surgery. The patients were discharged on the 10$14^{\text {th }}$ postoperative day. Stitch removal was done on the 14th Day. In the first two weeks patients not allowed weight bearing and next 4 weeks allowed toe touch weight bearing. Partial weight bearing with bilateral axillary crutches was allowed after adequate callus formation and full weight bearing was individualized depending on the patients, stability of fracture fixation. Clinical and radiographic follow-ups were done at 4 week, 6 week, two month, four month intervals, and at one year. The Modified Harris hip score (MMHS) used to evaluate the functional outcome of surgery ${ }^{[6]}$. Preinjury MMHS is calculated and post operative MMHS calculated at discharge, 6 weeks, 4 month and one year.

\section{Figure 1}

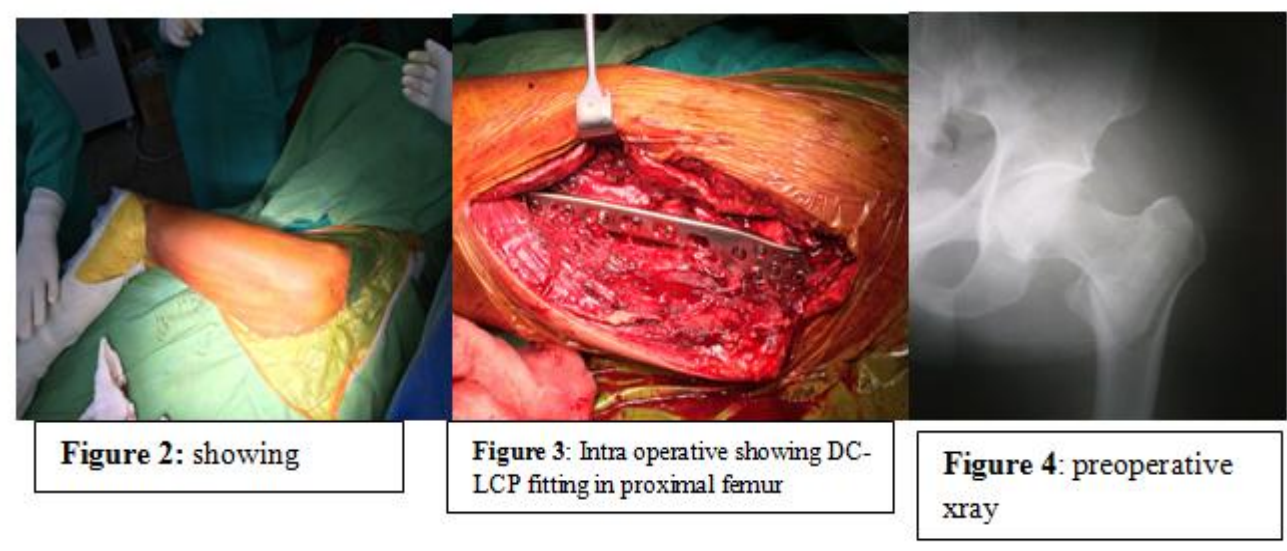




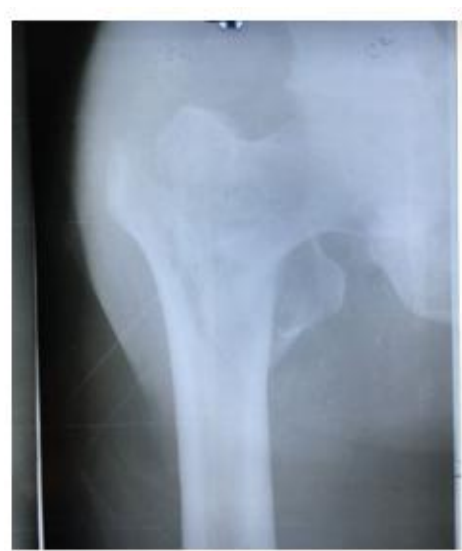

Figure 5: preoperative xray

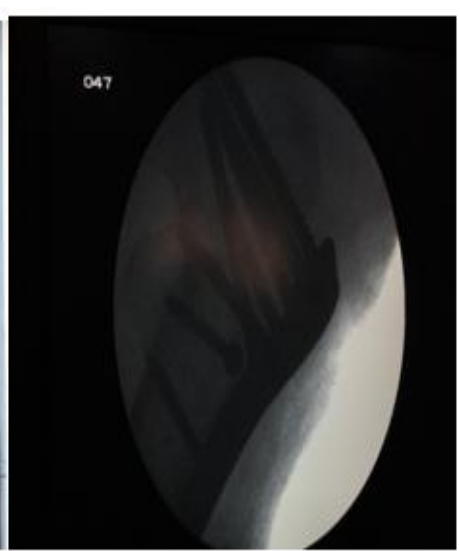

Figure 6: Intraoperative xray after fixation

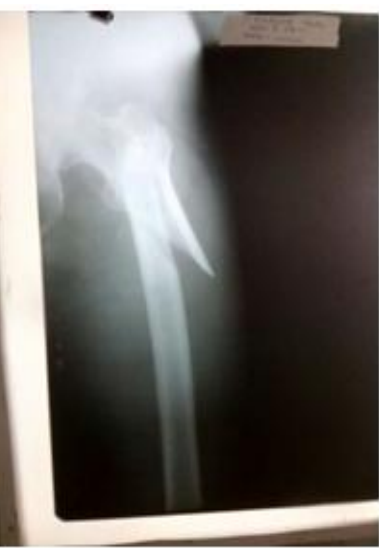

Figure 7: preoperative xray

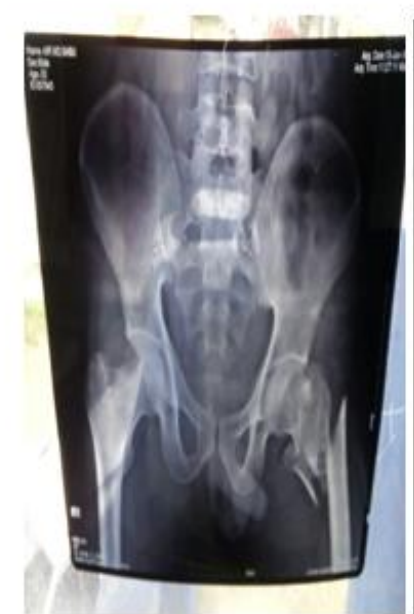

Figure 8: pre operative xray

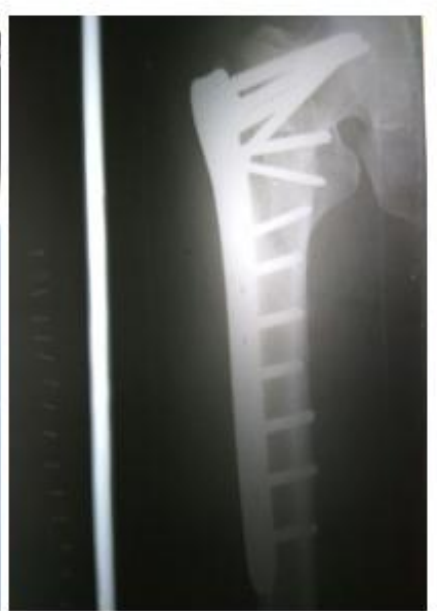

Figure 9: post operative xray

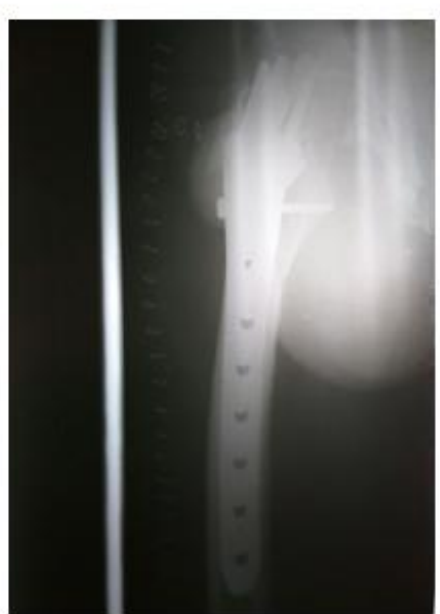

Figure 10: postoperative xray lateral view

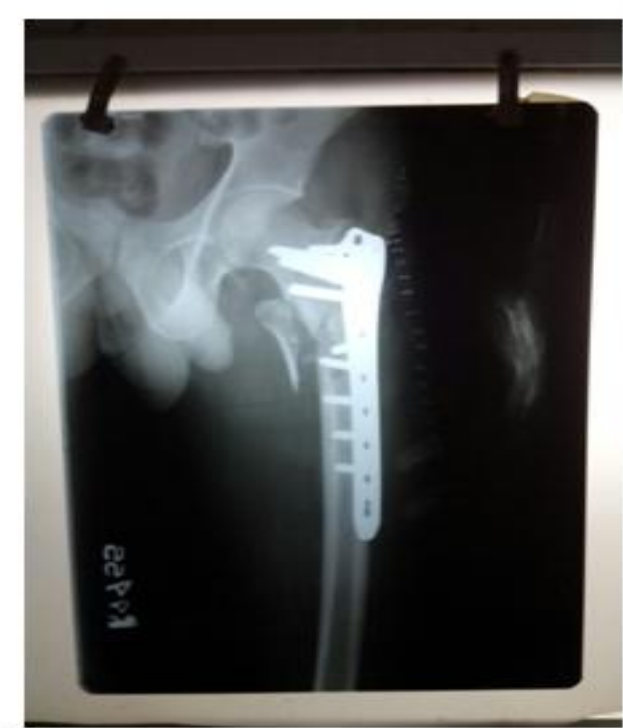

Figure 10: postoperative xray AP view

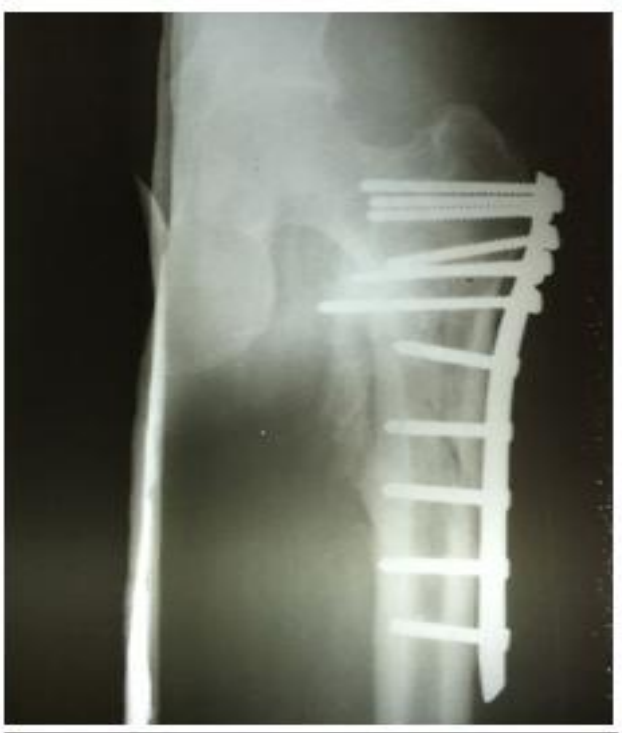

Figure 11: follow up xray at 3 months 


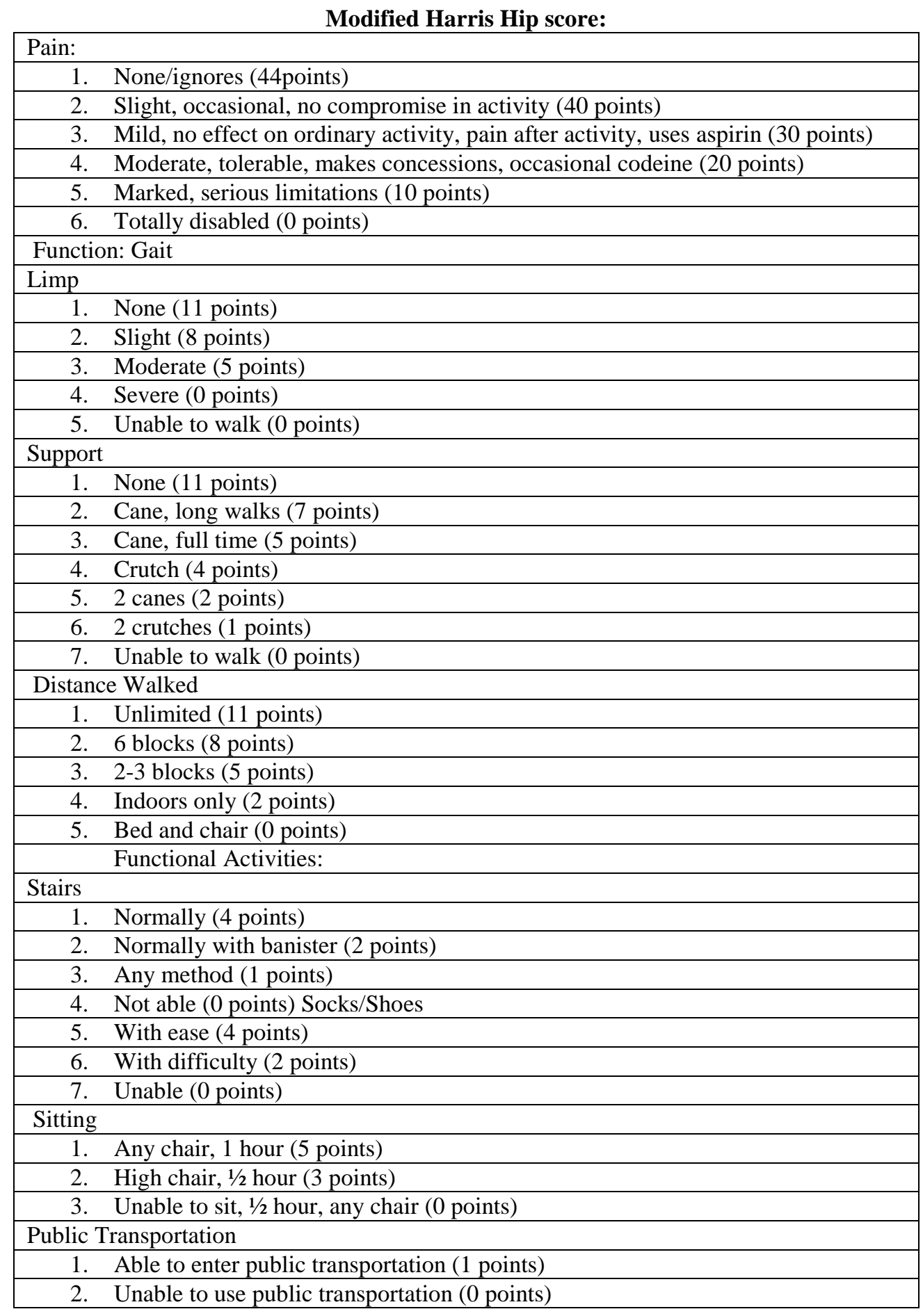

\section{RESULTS}

Thirty consecutive patients were included in this study. Twenty two patients (73.3\%) were male and 8 patients $(26.6 \%)$ were female. Mean age was $45.4 \pm 21.2$ years, mean weight was $65.7 \pm 12$ kilograms, and mean height was $161.1 \pm 8.6$ centimetres. Twelve patients $(40 \%)$ were smokers. Sixteen patients (53.3\%) had AO type 32B fracture, while nine patients $(30 \%)$ and five patients $(16.6 \%)$ were classified as AO type $32 \mathrm{~A}$ and $32 \mathrm{C}$ respectively. Road traffic accidents - accounted for 21 patients (70\%). Average time to fixation was $10.3 \pm 3.9$ days and average hospital stay was $21.5 \pm 5.6$ days. Mean operative time was $100 \pm 22$ minutes and mean blood loss was $553 \pm 276 \mathrm{ml}$. Mean follow-ups were $11 \pm 6$ months (range 6 to 19 months). 27 fractures $(90 \%)$ achieved union, average union time in 14.5 weeks Ranging from 10 weeks to 19 weeks. while three patients $(10 \%)$ had complications. In one patient the plate had broken, one had broken screw and non-union of the fracture. At the end of the follow-ups, 29 patients (96.6\%) were community ambulators. The mean pre-injury 
MHHS was 74 (Maximum of which was 91). Percentage in the return to pre-trauma activity was assessed with this. Mean value reached to 71 gradually over 4 month post operative period

\section{Modified Harris hip score increase over time}

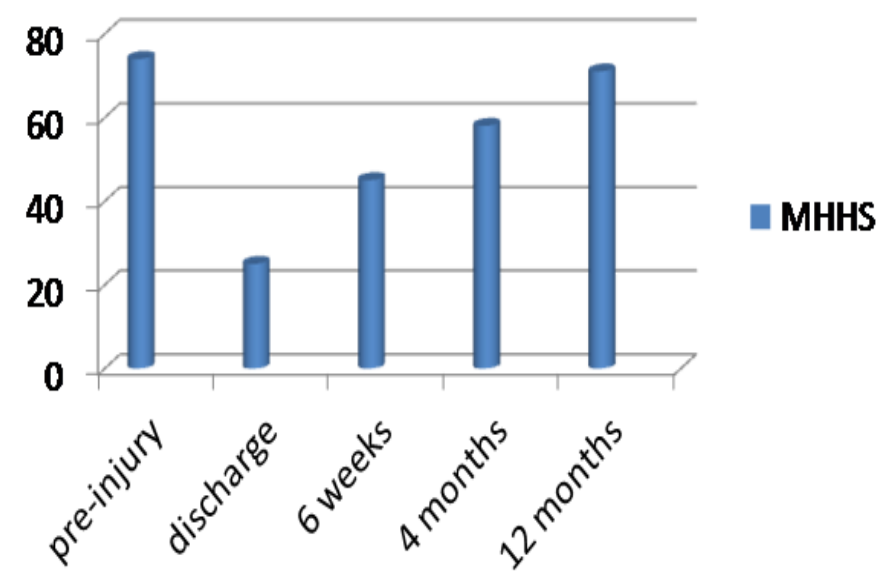

\section{Discussion}

Primary goal of subtrochanteric fracture treatment is to achieve rigid fixation and adequate union with optimal functional out come. Subtrochanteric fractures treatment is debatable as many types implants are being used. The implant choices of femoral subtrochanteric fractures can be divided mainly into two groups: cephalomeduallary hip nails and lateral plate-screw systems. Stable subtrochanteric fracture can be treated successfully with conventional implants, such as cephalomedullary nails, sliding hip screws and angular blade plates. However, comminuted and unstable subtrochanteric fractures are challenging injuries that are prone to complications ${ }^{[1]}$. Intramedullary device showed increased fracture stability when compared to extramedullary devices ${ }^{[7]}$. Even the inherently unstable fractures can be stabilised by use of intramedullary nail fixation in peritrochantric fractures and it is easy, fast to apply and guarantee stability ${ }^{[8,9]}$. However, Parker and Handoll's meta-analysis of all prospective randomized trials comparing intramedullary to extramedullary devices did not support the perceived superiority of nails. They failed to find statistically significant differences in mortality, infection, non-union, cut-out, and blood loss, operative time and radiation time in 3500 patients ${ }^{[10]}$. The authors of this meta-analysis concluded that the sliding hip screw was a better fixation device for intertrochanteric fractures than the intramedullary nail. But they also admitted that no concrete conclusions could be drawn from existing publications regarding unstable fractures, especially of the reverse obliquity variety. Jiang and his metaanalysis of randomized controlled trials had a similar view ${ }^{[11]}$. After intramedullary nails fixation, stiffness and a high axial load can result in failure, which is more likely to happen in second-generation cepholomeduallary nails than in the first-generation ones in unstable subtrochanteric fractures ${ }^{[12]}$. Therefore, evaluation of their results is difficult and controversial especially for subtrochanteric fractures. The dynamic compression hip screw (DHS) has been a popular method of internal fixation for subtrochanteric fractures ${ }^{[13-17]}$. It provides compression along the femoral neck, and if the reduced fracture is stable, load-sharing between the bone and implant can occur ${ }^{[18]}$. However, if the fracture is not stable, progressive medial displacement of the femoral shaft can occur, which may result in fixation failure and lead to non-union. Failures increase 7 fold if medialization of more than $1 / 3$ of the femoral diameter at the fracture site occurs ${ }^{[19]}$. Progressive varus collapse of the femoral head with proximal migration and eventual cutting out of the femoral head screw was the most common mode of mechanical failure of the sliding hip screw ${ }^{[17]}$.

The concept of the DHS with a trochanteric stabilizing plate is to prevent or reduce medial displacement. However, if the trochanteric stabilizing plate impedes further compression of the fracture before the fracture has become stable, the ends may angulate into varus with lag screws cut-out, breaking the plate or loosening as a result. Even in dealing with intertrochanteric fracture which is proven to be suitable for DHS, failures can exceed $15 \%$ when sliding hip screws are used ${ }^{[19,20]}$. In unstable subtrochanteric fractures with fragments that cannot be reduced by close reduction in a traction table, proximal lateral femur should be exposed open to reduce the fracture ${ }^{[21]}$. Medullary nails do not present the same advantage of the minimally invasive procedures. When using cepholomeduallary hip nails to fix comminuted subtrochanteric fractures with the lateral wall ruptured or with a lateral fragment, the reaming of proximal femur would distract the fragments and cause peritrochanteric instability. The use of binding wire affects the blood supply at the fracture site, causing delayed union or non-union. So under these circumstances locking compression plates offers the following advantages and disadvantages for femoral subtrochanteric fractures. The plate is placed at the lateral 
side of the proximal femur and can provide a stress shield for the lateral fragment, preventing the lateral migration of proximal fragments ${ }^{[2,23,24]}$. This characteristic is similar to that of the percutaneous compression plates (PCCP) designed by Gotfried, which can not only prevent rotation of proximal femoral head fragment, but also control the locked compression of the fragments ${ }^{[25]}$. The use of a DHS or DCS (dynamic condylar screw) provides no stress shielding, and the proximal fragment excessively slides along the axial lag screw. LCP, however, has clear differences. As the screws lock with the plate, the system is just like an external fixator frame, which can hold all the major fragments without lateral stress on the greater trochanter fragment ${ }^{[26]}$. Dissection of periosteum is not always needed, and some minimally invasive techniques can be used to reduce blood loss. As precise reduction and strong fixation are the main objective of the operation, closed reduction may not be able to achieve this goal but open reduction can. In fracture with proximal extension, the quality of the bone fixation is critical and, despite the development of anatomic plates (such as proximal femoral locking compression plate) may be endangered when there are too few proximal screws. To resolve this issue, we recommend using a reversed LCP anatomic distal femoral Less Invasive Stabilization System (LISS) locking plate: e.g., a left distal femoral plate for femoral fracture on right-hip implant ${ }^{[6]}$. The greater trochanter fragment and the lateral trochanteric wall play an important role in stability after implant fixation of subtrochanteric fractures. The distal femoral plate can be a feasible alternative for the treatment of unstable subtrochanteric fractures because it provides proper fixation of the lateral fragments, prevents the lateral migration of proximal fragments and stable fixation with more number of proximal screws.

In our study $90 \%$ of fracture united with average time of union of 14.5 weeks. Our results are comparable to other studies and feasible alternative for treatment of subtrochantric fractures with ruptured lateral wall where cephalomedullary device cannot be used and where a plate is needed with more number of proximal screws. Further studies are required to prove the outcome and effectiveness with large number of patients and with experienced surgeons.

\section{Conclusion}

The distal femoral locking compression plate of contralateral side represents a feasible alternative for the treatment of subtrochanteric fractures when properly performed. Further clinical studies are necessary to show its role in the treatment of these fractures.

\section{References}

[1]. Craig NJ, Maffulli N. Subtrochanteric fractures: current management options. Disabil Rehabil. 2005;27(1819):1181-90.

[2]. Bojan AJ, Beimel C, Taglang G, Collin D, Ekholm C, Jonsson A. Critical factors in cut-out complication after gamma nail treatment of proximal femoral fractures. BMC Musculoskelet Disord. 2013; 14(1): 1

[3]. Burnei C, Popescu G, Barbu D, Capraru F. Intramedullary osteosynthesis versus plate osteosynthesis in subtrochanteric fractures. J Med Life. 2011 14; 4(4): 324-9.

[4]. Celebi L, Can M, Muratli HH, Yagmurlu MF, Yuksel HY, Bicimoglu A. Indirect reduction and biological internal fixation of comminuted subtrochanteric fractures of the femur. Injury. 2006; 37(8): 740-50.

[5]. Ehlingera M, Brinkerta D, Bessea J, Adama P, Arlettazb Y, Bonnomet F, Reversed anatomic distal femur locking plate for periprosthetic hip fracture fixation. Orthopedics and traumotology:surgery and research. 2011 97,560-4.

[6]. Harris WH (1969) Traumatic arthritis of the hip after dislocation and acetabular fractures: treatment by mold arthroplasty. An end result study using a new method of result evaluation. J Bone Joint Surg Am 51(4):737-755.

[7]. Forward DP, Doro CJ, O'Toole RV, Kim H, Floyd JC, Sciadini MF, et al. A biomechanical comparison of a locking plate, a nail, and a 95 degrees angled blade plate for fixation of subtrochanteric femoral fractures. J Orthop Trauma. 2012; 26(6): 334-40.

[8]. Park SY, Yang KH, Yoo JH, Yoon HK, Park HW. The treatment of reverse obliquity intertrochanteric fractures with the intramedullary hip nail. J Trauma. 2008;65(4):852-7.

[9]. Wiss DA, Brien WW. Subtrochanteric fractures of the femur: results of treatment by interlocking nailing . Clin Orthop Rel Res. 1992;(283):231-6.

[10]. Parker MJ, Handoll HH. Gamma and other cephalocondylic intramedullary nails versus extramedullary implants for extracapsular hip fractures in adults. Cochrane Database Syst Rev. 2008;(3):CD000093.

[11]. Jiang SD, Jiang LS, Zhao CQ, Dai LY. No advantages of Gamma nail over sliding hip screw in the management of peritrochanteric hip fractures: a meta-analysis of randomized controlled trials. Disabil Rehabil. 2008;30(7):493-7.

[12]. Ekström W, Karlsson-Thur C, Larsson S, Ragnarsson B, Alberts KA. Functional outcome in treatment of unstable trochanteric and subtrochanteric fractures with the proximal femoral nail and the Medoff sliding plate. J Orthop Trauma. 2007;21(1):18-25.

[13]. Larsson S, Friberg S, Hansson LI. Trochanteric fractures. Mobility, complications, and mortality in 607 cases treated with the sliding-screw technique. Clin Orthop Relat Res. 1990;(260):232-41.

[14]. Massoud EI. Fixation of subtrochanteric fractures : Does a technical optimization of the dynamic hip screw application improve the results? Strategies Trauma Limb Reconstr. 2009;4(2):65-71.

[15]. Kinast C, Bolhofner BR, Mast JW, Ganz R. Subtrochanteric fractures of the femur. Results of treatment with the 95 degrees condylar blade-plate. Clin Orthop Relat Res. 1989;(238):122-30.

[16]. Vaidya SV, Dholakia DB, Chatterjee A. The use of a dynamic condylar screw and biological reduction techniques for subtrochanteric femur fracture. Injury. 2003;34(2):123-8.

[17]. Chirodian N, Arch B, Parker MJ. Sliding hip screw fixation of trochanteric hip fractures: outcome of 1024 procedures. Injury. 2005;36(6):793-800.

[18]. Haynes RC, Pöll RG, Miles AW, Weston RB. Failure of femoral head fixation: a cadaveric analysis of lag screw cut-out with the gamma locking nail and AO dynamic hip screw. Injury. 1997;28(5-6):337-41.

[19]. Watson JT, Moed BR, Cramer KE, Karges DE. Comparison of the compression hip screw with the Medoff sliding plate for intertrochanteric fractures. Clin Orthop Relat Res. 1998;(348):79-86. 
[20]. Davis TR, Sher JL, Horsman A, Simpson M, Porter BB, Checketts RG. Intertrochanteric femoral fractures. Mechanical failure after internal fixation. J Bone Joint Surg Br. 1990;72(1):26-31.

[21]. Sanders S, Egol KA. Adult periarticular locking plates for the treatment of pediatric and adolescent subtrochanteric hip fractures. Bull NYU Hosp Jt Dis. 2009;67(4):370-3.

[22]. Hasenboehler EA, Agudelo JF, Morgan SJ, Smith WR, Hak DJ, Stahel PF. Treatment of complex proximal femoral fractures with the proximal femur locking compression plate. Ortopedia. 2007;30(8):618-23.

[23]. Lundy DW, Acevedo JI, Ganey TM, Ogden JA, Hutton WC. Mechanical comparison of plates used in the treatment of unstable subtrochanteric femur fractures. J Orthop Trauma. 1999;13(8):534-8.

[24]. Zha GC, Chen ZL, Qi XB, Sun JY. Treatment of pertrochanteric fractures with a proximal femur locking compression plate. Injury. 2011;42(11):1294-9.

[25]. Langford J, Pillai G, Ugliailoro AD, Yang E. Perioperative lateral trochanteric wall fractures: sliding hip screw versus percutaneous compression plate for intertrochanteric hip fractures. J Orthop Trauma. 2011;25(4):191-5.

[26]. Egol KA, Kubiak EN, Fulkerson E, Kummer FJ, Koval KJ. Biomechanics of locked plates and screws. J Orthop Trauma. 2004;18(8):488-93.

*Roel Langshong. "Fixation of Subtrochantric Fractures Using Distal Femoral Locking Compression Plate of Contralateral Side." IOSR Journal of Dental and Medical Sciences (IOSR-JDMS) 16.7 (2017): 39-45. 